\title{
The Equation of State of HF Under Shock Compression
}

\author{
Laurence E. Fried
}

W. Michael Howard

This paper was prepared for submittal to the

11 th APS Topical Conference on Shock Compression

of Condensed Matter

Snowbird, UT

June 27-July 2, 1999

June 1999

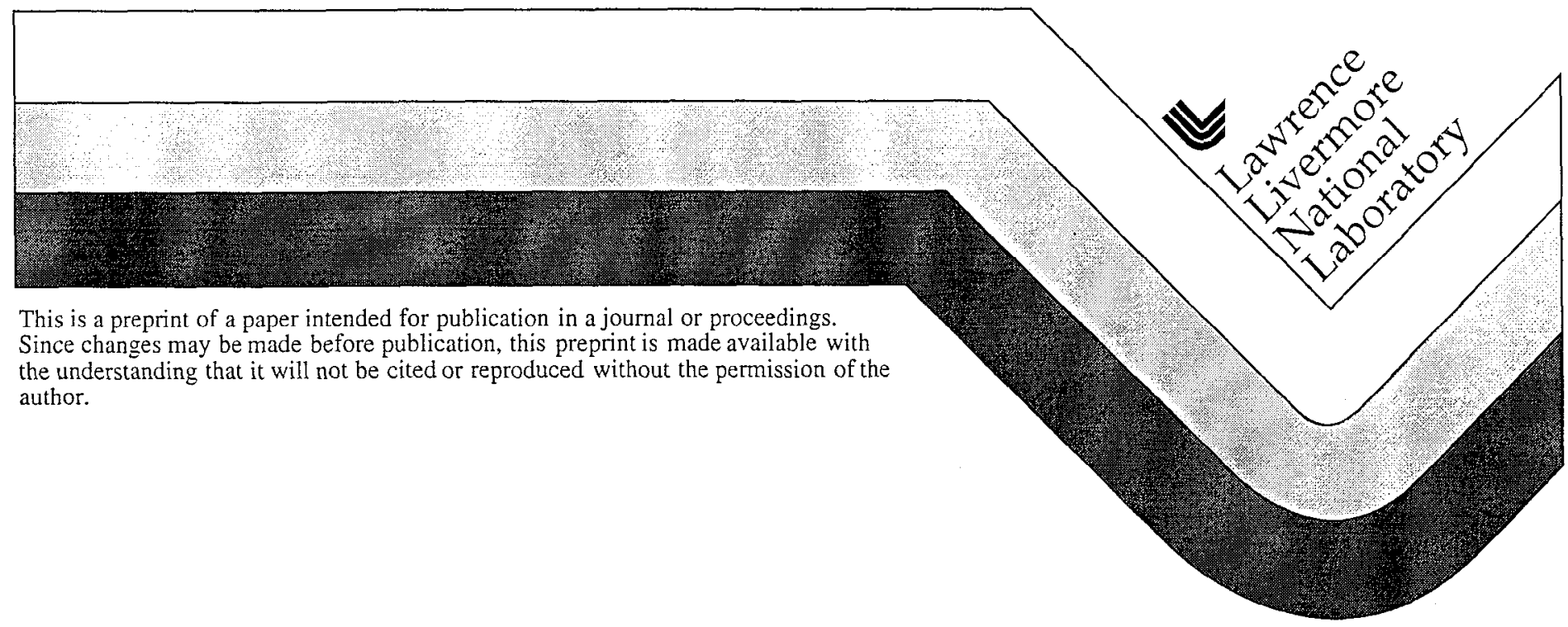




\section{DISCLAIMER}

This document was prepared as an account of work sponsored by an agency of the United States Government. Neither the United States Government nor the University of California nor any of their employees, makes any warranty, express or implied, or assumes any legal liability or responsibility for the accuracy, completeness, or usefulness of any information, apparatus, product, or process

disclosed, or represents that its use would not infringe privately owned rights. Reference herein to any specific commercial product, process, or service by trade name, trademark, manufacturer, or otherwise, does not necessarily constitute or imply its endorsement, recommendation, or favoring by the United States Government or the University of California. The views and opinions of authors expressed herein do not necessarily state or reflect those of the United States Government or the University of California, and shall not be used for advertising or product endorsement purposes. 


\title{
THE EQUATION OF STATE OF HF UNDER SHOCK COMPRESSION
}

\author{
Laurence E. Fried and W. Michael Howard \\ Lawrence Livermore National Laboratory \\ University of California \\ Livermore, CA 94551
}

\begin{abstract}
We develop a model of chemical equilibrium mixtures containing the elements $\mathrm{H}, \mathrm{C}, \mathrm{F}$. We show that the shock response of a wide variety of molecular and polymeric fluorocarbons can be modeled as a chemical equilibrium mixture of a small number of dissociation product molecules. HF is known to strongly associate in the supercritical fluid phase. We predict that such an association also occurs under shock conditions.
\end{abstract}

\section{INTRODUCTION}

Many organic materials decompose into a chemical equilibrium of small molecules under shock conditions. Notable examples are the dissociation of $\mathrm{N}_{2}$ into atomic $N$ at pressures upward of $30 \mathrm{GPa}[1]$, and the dissociation of hydrocarbons into solid carbon, hydrogen, and a variety of simple hydrocarbons[2]. Morris et al.[3] have performed recovery experiments on shocked polyethylene, and found that dissociation to $\mathrm{H}_{2}$ and a mixture of hydrocarbons occurs at pressures exceeding $19 \mathrm{GPa}$. The generality of this phenomenon, however, has not been fully established.

In the present paper, we argue that fluorocarbons undergo a similar dissociation process. There is some experimental evidence to support this assumption. Recovery experiments on shocked polytetrafluoroethylene[4] (PTFE, commonly known by the commercial name Teflon) have indicated the onset of decomposition at pressures exceeding 34 GPa. Given the well-known stability of PTFE, it is likely that most other organics will undergo similar decompositions when shocked.

\section{METHOD}

Chemical equilibrium is found using the Cheetah thermochemical code[5]. Gibbs' conditions for chemical equilibrium are solved along with mass balance and two additional equations specifying the thermodynamic state (i.e. the desired pressure and temperature).

The fluid is modeled as a mixture interacting with the potential energy function

$$
\begin{aligned}
& V(r)=\frac{\epsilon}{\alpha-6}\left[6 e^{\alpha\left(1-r / r_{m}\right)}\right. \\
& \left.-\alpha\left(r_{m} / r\right)^{6}\right] \quad ; r>r_{c} \\
& V(r)=\quad \infty \quad ; r \leq r_{c}
\end{aligned}
$$

Here, $\epsilon$ is the depth of the attractive well between particles, $r_{m}$ is the position of the potential well minimum, and $\alpha$ controls the steepness of the repulsive part of the potential. $r_{c}$ is defined as the position of the potential maximum. The "hard core" is customarily added for distances less than $r_{\mathrm{c}}$ to avoid the unphysical singularity in the potential function as $r \rightarrow 0$. The HMSAMC equation of state[6] was used to describe the excess free energy.

\section{DETERMINATION OF MODEL PARAME- TERS}

Wc usc a modificd Murnaghan equation of statc as follows:

$$
V=V_{0}\left[n \kappa P+\exp \left\{-\alpha\left(T-T_{0}\right)\right\}\right]^{-1 / n}
$$

$V_{0}$ is the molar volume when $P=0$ and $T=T_{0} . \kappa$ is the inverse of the isothermal bulk modulus. $T_{0}$ is the temperature of the reference isotherm, taken to be $298.15 \mathrm{~K}$ here. $\alpha$ is the volumetric coefficient of thermal expansion. $n$ is the derivative $d B\left(P, T_{0}\right) / d P$, where $B$ is the bulk modulus. 
A complete equation of state for the free energy may be derived once the isobaric heat capacity $C_{p}$ at 1 ATM is specified. We use a simple Einstein oscillator model for the heat capacity:

$$
C_{p}(1 \mathrm{ATM}, T)=3 R(\theta / T)^{2} \frac{e^{\theta / T}}{\left(e^{\theta / T}-1\right)^{2}}
$$

Thermodynamic integration of Eq. 3 along with Eq. 4 leads to a simple analytical form for the free energy. Parameters used are given in Table 1.

$\begin{array}{lllll}\text { Phase } & V_{0} & \alpha & \mathrm{B} & \mathrm{n} \\ \text { graphite } & 5.29 & 0.23 & 33.8 & 8.9 \\ \text { diamond } & 3.42 & 0.02 & 441.5 & 4.0 \\ \text { liquid } & 7.07 & 0.23 & 11.0 & 4.0 \\ \quad \text { Phase } & \Delta H_{0} & \Delta S_{0} & \theta & \\ \text { graphite } & 0.0 & 5.74 & 1280 \\ \text { diamond } & 1.9 & 2.36 & 1411 \\ \text { liquid } & 90.0 & 27.5 & 1280\end{array}$

Table 1: Parameters for the carbon equation of state. $V_{0}$ is expressed in cc/mol, $\alpha$ is in units of $10^{-4} \mathrm{~K}^{-1}$, $\mathrm{B}$ is in GPa, $\Delta H_{0}$ is in $\mathrm{kJ} / \mathrm{mol}$, and $\Delta S_{0}$ is in $\mathrm{J} / \mathrm{mol}-$ $\mathrm{K}$, and theta is in degrees $\mathrm{K}$.

We now specify the sources of experimental data used in the calculations that follow. The shock Hugoniot data for polyethylene, n-hexane, cyclohexane, benzene, PVF2, and PTFE comes from Marsh[7]. We use static compression data for $\mathrm{CH}_{2} \mathrm{~F}_{2}$ [8], $\mathrm{HF}[9], \mathrm{C}_{2} \mathrm{H}_{4}, \mathrm{CH}_{4}$, and $\mathrm{C}_{2} \mathrm{H}_{6}$. Experimental shock Hugoniot data are plotted with an estimated $1 \%$ error bar in the volume, unless the author specified an error bar, in which case that value was used.

We next discuss the fluorocarbon model. To our knowledge, high pressure equation of state measurements have not been performed on $F_{2}$. We use exp-6 parameters for $\mathrm{F}_{2}$ estimated by Zerilli and Jones[10]. We considered the shock behavior of PTFE in order to determine parameters for $\mathrm{CF}_{4}$. We predict that PTFE decomposes into a fluid phase composed mostly of $\mathrm{CF}_{4}$, and carbon in the diamond phase. We found an unusually high value of the potential steepness parameter $\alpha$. We note that Zerilli and Jones[10] also obtained a very steep potential for $\mathrm{CF}_{4}$ by spherically averaging a Lennard-Jones potential. The fact that steep potentials were obtained in two distinct ways suggests that $\mathrm{CF}_{4}$ may have an unusually steep repulsive potential energy surface. We next determined the $\mathrm{CH}_{2} \mathrm{~F}_{2}$ parameters by matching static compression data.

$\mathrm{HF}$ is known to strongly associate, in the gaseous, liquid, and fluid phases. We have determined a simple $\mathrm{HF}$ association model that matches both high and low pressure data. There is insufficient experimental data on HF to uniquely determine the exp-6 parameters of each associated species. Instead, we use the following simple rules to relate the properties of the clusters to that of HF:

$$
\begin{aligned}
r_{m, N} & =N^{1 / 3} r_{m, 1} \\
\epsilon_{N} & =\epsilon_{1} \\
\alpha_{N} & =\alpha_{1} \\
\Delta H_{0, N} & =N \Delta H_{0,1}+(N-1) \Delta H_{c} \\
\Delta S_{0, N} & =N \Delta S_{0,1}+(N-1) \Delta S_{c}
\end{aligned}
$$

Herc, $N$ is the cluster size. $\Delta H_{0, N}$ is the heat of formation of the cluster, and $\Delta H_{c}$ is the enthalpy of transition from the monomer to the cluster. $\Delta S_{0, N}$ is the standard enthalpy of the cluster, and $\Delta S_{c}$ is the entropy of transition from the monomer to the cluster.

The motivation for the cluster model is to determine the simplest possible model that will match both the low pressure static compression of supercritical HF, and the shock Hugoniot of PVF2. The current model succeeds in this regard, although we cannot claim that the description of individual cluster species is quantitatively accurate. We have found that it is possible to match the shock Hugoniot of PVF2 without the association model, but the static compression requires an explicit treatment of association.

An important consideration in constructing the cluster model is which species ( $N$ values) to include. The JANAF compilation includes estimated standard state thermodynamic parameters up to $N=7$. Successful equation of state models of $\mathrm{HF}$ have been derived based on monomer and hexamer species alone[11]. We found that this approach could match the static compression data to within $5 \%$, while the present model is accurate to within $2 \%$. It would be possible to include higher cluster species in the present model, but it is not known whether such species are actually produced in any significant quan- 
tity. We therefore decided to limit our model to only those clusters described by JANAF.

The JANAF compilation provides estimates of $\Delta H_{0, N}$ and $\Delta S_{0, N}$. We found that adjusting their values slightly (by roughly $5 \mathrm{~kJ} / \mathrm{mol}$ in $\Delta H_{c}$ and $0.003 \mathrm{~kJ} / \mathrm{mol}-\mathrm{K}$ in $\Delta S_{c}$ ) was necessary to reproduce measured isotherms accurately. We found that using $\Delta H_{c}=-32.6 \mathrm{~kJ} / \mathrm{mol}$ and $\Delta S_{c}=-0.106$ $\mathrm{kJ} / \mathrm{mol}$ matched the data well. Parameters for the HF monomer are given in Table 2.

$\begin{array}{llll}\text { Species } & r_{m}(\AA) & \epsilon / k_{B}(\mathrm{~K}) & \alpha \\ \mathrm{H}_{2} & 3.502 & 19.7 & 12.072 \\ \mathrm{CH}_{4} & 4.316 & 138.8 & 12.356 \\ \mathrm{C}_{2} \mathrm{H}_{6} & 4.820 & 239.7 & 14.267 \\ \mathrm{C}_{2} \mathrm{H}_{4} & 4.682 & 203.0 & 12.597 \\ \mathrm{~F}_{2} & 3.800 & 92.2 & 13.000 \\ \mathrm{HF} & 3.716 & 339.0 & 13.464 \\ \mathrm{CH}_{2} \mathrm{~F}_{2} & 4.718 & 256.2 & 13.000 \\ \mathrm{CF}_{4} & 4.939 & 239.3 & 15.496\end{array}$

Table 2: Exponential-6 potential parameters for species contained in the supercritical fluid phase.

We show the calculated isotherms of HF in Figure 1. The calculated shock Hugoniot of PVF2 is shown in Figure 2. The HF model is seen to work equally well in the experimental pressure range of 0.01 to $75 \mathrm{GPa}$. We next consider the chemical concentrations predicted by our model. In Figure 3 we show the concentrations of the predominant species along the shock Hugoniot of PVF2. We predict that PVF2 dissociates into a fluid phase containing mostly HF clusters, and a solid phase containing diamond. $\mathrm{H}_{2}$ is seen to be present in significant, although smaller, quantities. The chemical concentrations are predicted to be roughly constant along the shock Hugoniot, with significant changes with pressure seen only in the minor species $\left((H F)_{6}, \mathrm{CF}_{4}\right)$.

Since HF is present in the most highly associated form included in our model, it is possible that further association into a polymeric phase may be thermodynamically favorable. This is outside the scope of the present exp-6 model with effective spherical particles. Our calculations suggest that the shock Hugoniots of PVF2 and other fluorocarbons may provide valuable insight into the high pressure equation of

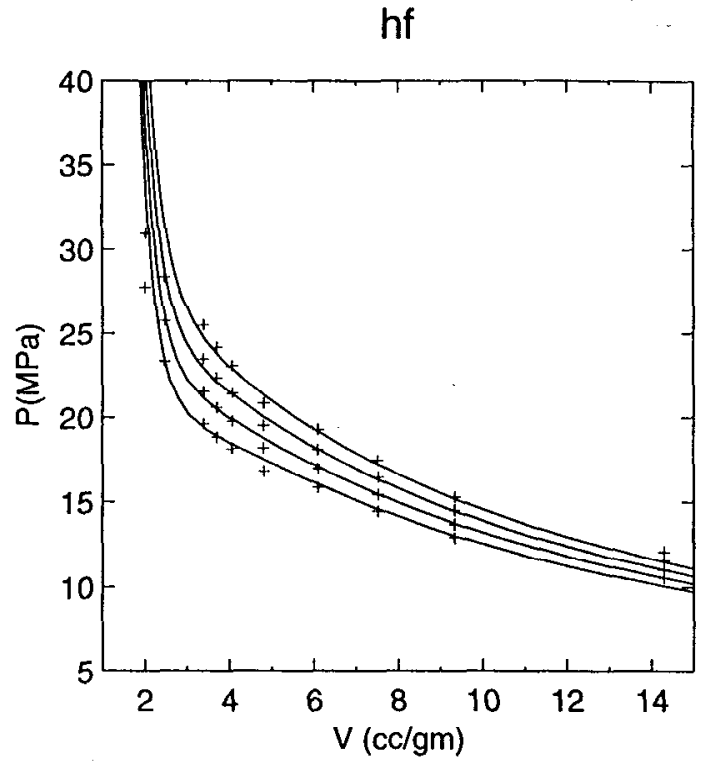

Figure 1: Measurements of the isotherms of $\mathrm{HF}$ at $543,553,563$, and $573 \mathrm{~K}$ (points) are compared to calculations of the present model (lines)

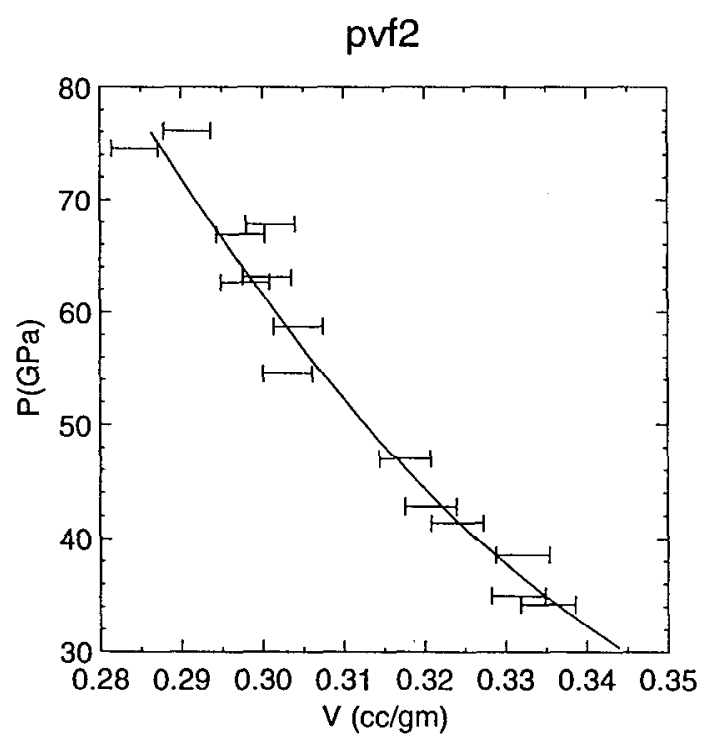

Figure 2: Measurements of the shock Hugoniot of PVF2 (error bars) are compared to calculations of the present model (line) 


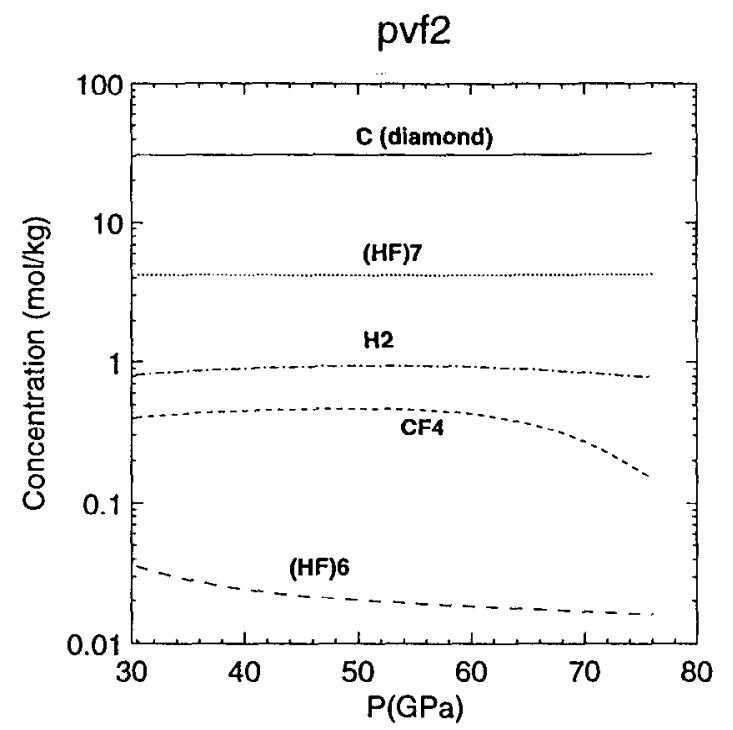

Figure 3: Predicted chemical concentrations along the reactive shock Hugoniot of PVF2.

state of HF.

\section{CONCLUSION}

In the present paper we have presented a reactive model of fluorocarbons based on a single supercritical fluid phase in equilibrium with carbon. The model was calibrated to a wide range of existing experimental static and shock data. Where sufficient data existed, we demanded that the model match both static and shock experiments. Our success in this regard here and in prior work[6] suggests that shock and static data may be successfully combined in a sufficiently general equation of state framework. Further work in extending this approach to a wide range of common molecules is underway. We hope that the eventual result will be a broadly applicable model of the cquation of state of reactive supcreritical fluids.

Our ability to model the behavior of shocked fluorocarbons helps to unify data that was previously apparently unrelated; the behavior of this class of materials under shocks over $35 \mathrm{GPa}$ are now related to the properties of a small set of simple decomposition products. The decomposition model has allowed us to extract useful high pressure equation of state data on HF from the shock response of chemically inert materials such as PVF2 and PVC. Since direct high pressure experimentation on HF is difficult, the data may be of use to other workers.

\section{ACKNOWLEDGEMENTS}

This work was performed under the auspices of the U. S. Department of Energy by the Lawrence Livermore National Laboratory under contract No. W7405-ENG-48. This work was supported by the Accelerated Strategic Computing Initiative (ASCI) at Lawrence I ivermore National Laboratory.

\section{References}

[1] W. J. Nellis et al., J. Chem. Phys. 94, 2244 (1991).

[2] W. J. Nellis et al., J. Chem. Phys. 80, 2789 (1984).

[3] C. E. Morris et al,, in Shock Compression of Condensed Matter-1989, edited by S. C. Schmidt, J. N. Johnson, and L. W. Davison (American Institute of Physics, New York, 1990), pp. 687-690.

[4] C. E. Morris, J. N. Fritz, and R. G. McQueen, J. Chem. Phys. 80, 5203 (1984).

[5] L. E. Fried, Cheetah 2.0 User's Manual, Lawrence Livermore National Laboratory, Livermore, CA 94550, 1998, manuscript number UCRL-MA117541 Rev. 5.

[6] L. E. Fried and W. M. Howard, J. Chem. Phys. 109, 7338 (1998)

[7] S. P. Marsh, LASL Shock Hugoniot Data (University of California Press, Berkeley, CA, 1980).

[8] P. F. Malbrunot et al., J. Chem. Eng. Data 13, 16 (1968).

[9] V. E. U. Franck and W. Spalthoff, Z. Elektrochem. 61, 348 (1957).

[10] F. J. Zerilli and H. D. Jones, in High-pressure science and technology-1993, AIP Conference Proceedings 309, edited by S. C. Schmidt, J. W. Shaner, G. A. Samara, and M. Ross (American Institute of Physics, New York, 1994), pp. 113-116.

[11] C. P. C. Kao, M. E. Paulaitis, G. A. Sweany, and M. Yokozeki, Fluid Phase Equilibria 108, 27 (1995). 